$\xi=$ 离

\title{
Determinants of modern contraceptive preference among mothers (15-49 years) in central zone, Tigray region, Ethiopia; qualitative study finding
}

\author{
Merhawi Gebremedhin ${ }^{1 *}$, Ayele Belachew ${ }^{2}$, Demeke Desta ${ }^{3}$ \\ ${ }^{1}$ Haramaya university, School of public health, Harar, Ethiopia \\ ${ }^{2}$ Addis Ababa University, department of epidemiology and biostatistics, Addis Ababa, Ethiopia \\ ${ }^{3}$ IPAS Ethiopia country office, Addis Ababa, Ethiopia \\ *Corresponding author E-mail: meriget12@gmail.com
}

\begin{abstract}
Contraceptive method choice is a fundamental indicator of quality of care in a family planning program. Contraceptive choice is one component of quality in family planning and offering minimum of three modern methods of contraceptives is a critical indicator. Onethird of developing countries have many skewed method mixes, which is a risky for discontinuation, contraceptive dissatisfaction and unintended pregnancy. In Ethiopia, the prevalence of contraceptive is highly skewed, $76 \%$ for injectable. Therefore, the purpose of qualitative study was to assess determinants of modern contraceptive preference among reproductive age (15-49 years) in Central Zone of Tigray.

Methodology: the study was conducted in the central zone of Tigray and community, and facility based qualitative cross-sectional study was applied. Six focus group discussion entails of reproductive age mothers and 15 In-depth Interview with health workers constitutes the sample. Data was first transcribed and then translated into English language. Open code software was applied to analyze data and data was coded segment by segment then categorized using thematic analysis to give meaning.

Result: community's awareness and acceptance to use modern contraceptives have improved from time to time. Contraceptive preference is determined by community acceptance, health care system problem, individual context and socio-cultural problem. For majority of respondents, preference to long acting contraceptive is mainly influenced by husband.

Conclusion: currently, women are preferring short-acting contraceptive preferably injectable than long acting.Implanon is preferred next to injectable. A strong information, education and communication that address all portions of the population and able to change the community's attitude should do at the grass root level.
\end{abstract}

Keywords: Age 15-49; Contraceptive Preference; Ethiopia; Qualitative Study.

\section{Introduction}

Contraception is one of the major determinants of fertility levels, and it practiced for many reasons, such as pregnancy delaying, limiting, avoiding medical risks, and controlling the world population (USAID, 2009). All individuals have the right to access, choice and the benefits of scientific progress in the selection of family planning methods' (2).Contraceptive Contraceptive choice is one component of quality of family planning and offering at least three modern methods of contraceptives is critical indicator to reproductive health commodity security (, Mesganaw F. 2005, UNFPA 2011).

Many elements need to be considered by women, men, or couples at any given point in their lifetimes when choosing the most appropriate contraceptive method. In other words, contraceptive preference is influenced by multiple elements such as safety, effectiveness, availability (including accessibility and affordability), Age, number and sex of living children and acceptability (WHO 1993, Eric et al.2007, USAID 2009, John et al. 2011). (See figure one)

According to WHO 2004, "Decision-making for contraceptive methods usually requires the need to make trade-offs among the different methods, with advantages and disadvantages of specific methods varying according to individual circumstances, perceptions and interpretations" (Andrew et al ., 2006). informed choice of contraceptive methods is an essential guiding principle. Contraceptive counseling, where applicable, may be an important contributor to the successful use of contraceptive methods (Charles et al., 2011).

Contraceptive has three main indicators- Contraceptive Prevalence Rate (CPR), unmet need for contraceptive and method mix (UNFPA, 2011).There 2011). There is neither "optimal" or "ideal" method mix recognized by the international reproductive health community nor single "best" contraceptive; rather, couples are encouraged to adopt the method with the most benefits and fewest drawbacks, based on their individual perceptions. However, there is often concern when a single method predominates in a country, suggesting some systematic limitation of contraceptive choice (Jane et al., 2000).

The practice of modern contraceptive in Ethiopia has been started by Ethiopian family guidance association more than four decades before. However, the prevalence to every modern contraceptive in general and the prevalence to long acting and permanent contraceptive, in particular, are remaining very low and despite the effort of Ethiopian ministry of health and its partners to increase the 
number of women who expected to use the long acting and permanent contraceptive, its progress is still not satisfactory. (Mengsitu et al 2000, FDRE 2011).

In 2011, about $18.7 \%$ of all women in Ethiopia were used modern contraceptive with share to injectable contraceptive accounts for 74.8\%. (EDHS, 2011). This indicates a high method mix skewness but there is no information, whether the uneven distribution or contraceptive method skewness is the result of health ser- vice/programs, properties of the method themselves (side effect, effectiveness, availability, acceptability), community acceptance and client characteristics (age, attitude, number of children). Hence, the aim of this study is to assess the determinants of modern contraceptive method's preference among child-bearing women.

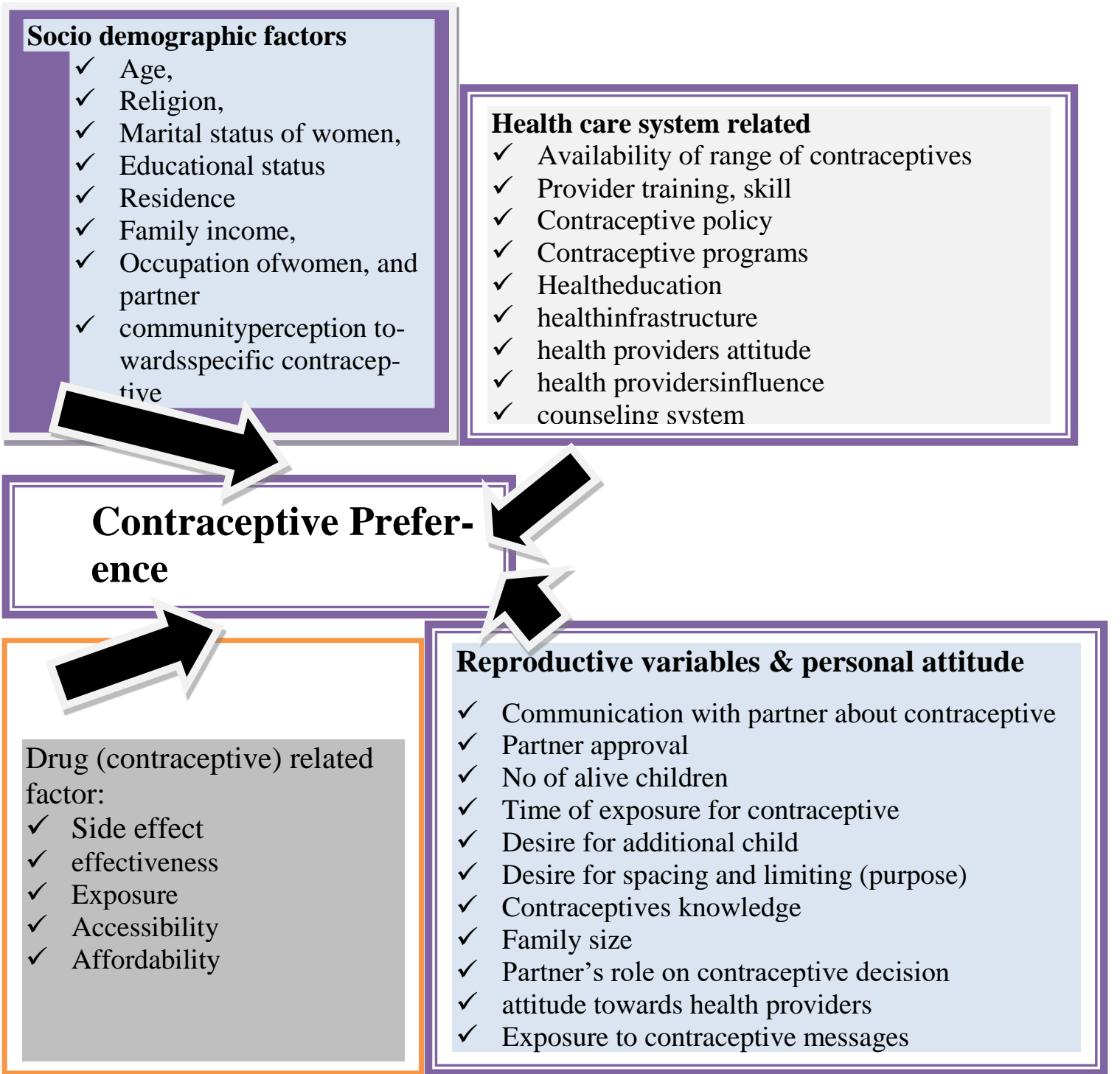

Fig. 1: Conceptual Frame Work for Qualitative Study on Determinants of Modern Contraceptive Preference among Mothers (15-49 Years) in Central Zone, Tigray Region, Ethiopia, 2013

\section{Methodology}

The study was conducted in Central Zone of Tigray, which is located in the Northern part of Ethiopia, $1050 \mathrm{~km}$ far from the capital, Addis Ababa. The Regional (Tigray) annual population growth rate is 2.5 (CSAE, 2007).The 2007). The Zone has 9 rural and 3 urban districts with 3 Hospitals and 57 health centers. About 631,972 female populations were residing in the Zone. (Population and housing census, 2007).). The study was carried out in February 2013.

A community and facility based qualitative descriptive crosssectional study was used. Source population was women (15-49 years) and Health professionals working at Health facilities and Health office in the zone. Purposively selected child-bearing women (15-49 years) and Health professionals were our study population.

Sample size was determined purposely. The sample sizes for IDI and FGD were 15 participants and six FGD groups respective- ly. Three from urban and three from rural FGD having 8-10 participants in each group were identified. Each member of the participant was selected and identified in collaboration with respective kebelle leaders and head of women association.

In order to understand the perspective on the community, particularly the women focus group discussants were select based on certain criteria. Some of the criteria we have used were residence, age, religion and Education background. The sampling for indepth interview was straight-forward, i.e. a total of 15 health professionals working at different level ( 2 rural and 2 urban health center service providers, 3 rural and 2 urban maternal and child health experts, 2 rural and 1 urban health center heads, 1 Hospital service providers, 1 health extension worker and 1 Hospital maternal and child health focal person,) were purposively selected and all have been interviewed.

Semi-structured open-ended guiding questions were used to collect raw data. Guiding questions was first prepared in English then translated to the local language -Tigrigna. Data collection was started after each participant has been signed in the consent form. 
Two female BSC nurse and two female diploma nurse who are native Tigrigna speakers were undertaken FGD and in-depth interview. Data collectors were paired into two (one BSC and one diploma), and the BSC serves as facilitator and the diploma one serves as note taker. Tape recorder was used to capture all notes. Recorded data was first transcribed keeping its originality and then translated into English. Consistency was checked for both transcription and translation by another people. The translated data was first changed to plain text and then transported in to the open code software for analysis. Data was coded line by line as well as by paragraph method. Thematic analysis supported by description was applied, and contraceptive determinant variables categorized into four themes.

Data collection was started after a written official permission has obtained from responsible organizations. First official letter was obtained from Research and Ethical committee of Addis Ababa University, School of Public Health. Supportive letters from Tigrai Regional Health Bureau, Axum Zonal Health office and selected Woreda Health administrator was obtained. Each participant signed independently, and data collection was begun after written consent was assured. FGD interview was conducted in respective kebele hall while, IDI was conducted in their office. Every interview has kept privacy and confidentiality.

Operational definition was given for main indicators, accordingly; Short-acting contraceptive (SAC) was defined as a contraceptive that requires more than one administration within a year and includes the pill, injectable, and barrier method like male and female condom meanwhile, Long Acting and Permanent Method (LAPM) were defined as a contraceptive used for more than one year after single administration and it includes Implants, IUCD, and tuba ligation or vasectomy.

\section{Result}

A total of 52 women found within the age interval of 22- 47 years were participated in the FGD session. Additionally, 15 in-depth interviews were performed. All IDI participants are health professionals. The mean age for FGD and IDI discussants was 32.9 and 40.7 years respectively. About $46.2 \%$ of the FGD and $50 \%$ of the IDI participants were elementary and degree holders respectively. Most of the discussants indicate that the community's awareness and acceptance to use modern contraceptives have improved through time, but it does not reach to a level expected by the government. Awareness and intention to use modern contraceptives are better among women than their male counterparts. Despite the increased number of contraceptive user's majority of the participants stated that, the community lacks the far-reaching advantages of contraceptive use like improving health of the women and children, as well as social and economic benefits. Religious believe, high desire of men to have more children, and the socio cultural drawback of the community was mentioned as a problem for low utilization of modern contraceptive.

Good, in the first time in which the contraceptive was introduced, the community was not aware of its advantage. However, this time, the community, particularly the youth are very aware of its advantage. In the first time it was taking much time to convince the mother and even their husbands were criticized for health education providers. They (the husband) said, "what do you mean by do not give birth" Female, 42, years.

In the case of permission to use contraceptive, still there are problems, so some of the females try to convince their husband to take contraceptive. However, some also take hidden. For example, I know as there are some Muslim women who did not use contraceptive because of their husband influence".Female, 40 years, depo user.

The community also has a different view on the different contraceptive types with more or less good attention towards the injectable contraceptive. According to FGD participants, long acting and some short-acting contraceptives like condom and pill are not much acceptable by the community in general and by contracep- tive users, in particular, providing that this is the main reason for contraceptive method skeweness.

I observe that most women consider injectable as good. I think the reason behind is that, one, if you stop it, the menses comes immediately. It has a good appetite. Increases weight. The other reason is, it serves for short time, and it is easy to get pregnancy if you change your plan. In my observation, most women hate the pill; because, it may aggravate gastric problem. The other contraceptive that hated by the community is the loop. I think it could disappear inside the uterus, so I prefer injectable." Female, 45 years, Concerning the contraceptive supply, though, it is not common; the health professionals indicate that there is some contraceptive stock out commonly for injectable contraceptive. The main reason for contraceptive stock out is its way of distribution that is, contraceptive is supplied based on total population in the catchment area; it is not based on the consumption rate in the respective facilities. This leads unnecessary wastage in one area and limitation of supply in the other place. However, a majority of the health professionals stated that absence of skilled health professional is not the problem for their respective health facility.

Women should prefer or choose the contraceptive they want providing that informed choice is in place. It is up to individual women to prefer contraceptive, but this is not the case in this finding in that, a majority of the service providers replied that majority of contraceptive users have no power or face difficulty to prefer the contraceptive they want except for injectable form.

Preference to long acting contraceptive was mainly influenced by husband; many of the service providers indicate that even though, many women have an interest to use the long-acting contraceptive, but they do not choose it for fear of their respective husband. Even some service providers witnessed that there are some male partners who had been made conflict with health professionals after his wife had taken the long-acting contraceptive. Another provider witnessed that some male partners even follow the footstep of his wife when he suspects that she went to health facility for contraceptive intake and create conflict with his wife and health care providers at the spot of the event.

Another cause for lack of confidence for long acting contraceptive choice is the pressure from family of husband, particularly mother in law. If one mother take contraceptive and stay without pregnancy for longer time, the mother in law will give her, a nickname so called 'Bazra'to mean that 'female mule' because female mules never give birth. The family of husband even encourages him to divorce her if she stays longer time without pregnancy.

Being educated mother, discussed with her male partner, having more than three children and being above the age of 35 years are some preconditions where mother can become confident to choose long acting contraceptives freely. A mother with those conditions has fewer chances to divorce by her husband, and that's why they choose the contraceptive without any fear.

Many women have no capacity to choose contraceptive properly. Those educated and those discussed with their husband are confident of choose the contraceptive they want. Most women choose the short acting without support from any person. Male 40 years, health center head.

The participants also mentioned many factors that make mothers to prefer one contraceptive from others and for the convenience of description; those factors are classified into four main themes with sub theme placed under each category. 
Table 1: Thematic Result of Qualitative Study, Central Zone, Tigray Region, Ethiopia 2013

Theme: Modern contraceptive method preference is influenced by 1 . Community attitude towards the specific contraceptive, 2 . Health Care System problem, 3. Reproductive history and personal attitude, and 4. Socio cultural factor.

\begin{tabular}{|c|c|c|c|c|}
\hline Category & 1) & $\begin{array}{l}\text { Community attitude } \\
\text { towards specific con- } \\
\text { traceptives }\end{array}$ & 2) & $\begin{array}{l}\text { Health care system } \\
\text { problem }\end{array}$ \\
\hline code & $\bullet$ & $\begin{array}{l}\text { Misperception about } \\
\text { contraceptives } \\
\text { Poor attention and } \\
\text { acceptance }\end{array}$ & $\begin{array}{l}\bullet \\
\bullet\end{array}$ & $\begin{array}{l}\text { Skill problem (Refuse } \\
\text { and failure to remove } \\
\text { Implants\& IUCD) } \\
\text { Programmatic prob- } \\
\text { lem ( Encourage for } \\
\text { LAPM, Influence } \\
\text { choice, Female fo- } \\
\text { cused FP, Discrimi- } \\
\text { nate contraceptives ) }\end{array}$ \\
\hline category & 3) & Individual context & 4) & Socio cultural factor \\
\hline code & $\begin{array}{l}\bullet \\
\bullet \\
\bullet\end{array}$ & $\begin{array}{l}\text { Lack of self-empower } \\
\text { Fear of complication } \\
\text { Social issues (Age or } \\
\text { Children based pref- } \\
\text { erence, adaptation, } \\
\text { Flexibility of preg- } \\
\text { nancy prevention } \\
\text { plan) }\end{array}$ & & $\begin{array}{l}\text { Community infor- } \\
\text { mation dynamics } \\
\text { Women's dependency } \\
\text { Social pressure (Hus- } \\
\text { band and family pres- } \\
\text { sure, Peer pressure } \\
\text { Religion pressure }\end{array}$ \\
\hline
\end{tabular}

Community attitude is one of the determinant factors for current contraceptive preference that is contraceptive/s that has low acceptance by the community are less likely to use by women compare to have high acceptance. In this study, community attitude influences contraceptive preference as a result of two main perspectives. Misperception about specific contraceptives, and Poor attention and acceptance. (See table one)

Majority of the FGD and IDI discussants agreed that misperception about specific contraceptive is one of the common problems for discrimination of contraceptive preference. Many of the FGD participants describe that pill is not chosen by women because it can accumulate in the uterus and/or stomach. According to the participants' view, unless a woman made a curettage that is manual removal of the pill from the accumulated part which is the uterus or stomach, she could not give birth at a time she wants to have birth. In other words, pill can accumulate in the uterus and/or stomach and can cause infertility so to become fertile; the mother should do curettage. (See annex one)

Furthermore, the community also believes that pill can cause gastritis, cloasma, cancer, and does not prevent pregnancy correctly. The finding showed that pill has the high failure rate, and is not good for those mothers who do not have balanced diet more specifically for female farmers. As a result of this many women are not interested to prefer the pill. (See annex one)

IDI and FGD discussants share the dual advantage of condom use, but the majority of contraceptive users are not interested to prefer condom. The reason is that it creates untrustworthiness over the partner who requests for condom use. Participants also respond that condom does not have a sexual pleasure, and the lubricant of a condom by itself causes a woman to conceive. (See annex one) Some of the misperceptions about injectable contraceptive as mentioned by discussants were body spasm, loss of sexual desire, pregnancy out of uterus, and cancer. Despite these misperceptions, the participant said that majority of contraceptive users have good attitude to prefer it. Meanwhile, the participants also added that infertility, hair loss, body soreness, loss of body weight, fetal anomaly and paralysis of hand where the contraceptives inserted are some of the common perceptional problems related to implants. Participants added that these and other related problems were the main threat for failure of implant's preference. (See annex one).

Misperception about IUCD includes it can disappear from the uterus hence it suffer the mother during removal and lead to a backbone operation, causes uterine prolapse, discomfort during sex and being in doubtfulness on its effective prevention of pregnancy for twelve years are few from others. (See annex one)
As mentioned by participants, most of the long acting contraceptives have no-good acceptance by the community. Meanwhile, bad rumors about long acting contraceptives are highly disseminated inside the community. This led women to hate long acting contraceptives. For example, the community believes that using a contraceptive for long time led a woman to give an abnormal child (mental or physical). Two participants witnessed as this is really happened in their community.

Almost all discussants agreed that injectable is the most preferable contraceptives by the community in general and by women in particular. Participants also indicated as implants are preferred next to injectable. Condom and pill are highly known in the community, but they are less preferable than injectable. Similarly, discussants said that IUCD is much hated contraceptive by women

Health care system problems mainly programmatic and professional biases were the two commonly mentioned problems that made many women to have skewed contraceptive preference. (See table one).Participants indicate that the family planning program is mainly focused on female and all health educations and counseling in regarding to family planning are primarily emphasized on female. Nevertheless, pressure from husband and family, in particular, and the community in general is most important factor for contraceptive preference.

The FGD participants added that creating awareness among all segments within the population about the different type of contraceptive is best solution to reduce the uneven distribution of contraceptive preference. Majority of the FGD also stated that health professionals are highly interested to provide long acting contraceptive preferably the implants; even some discussants confirm that there are some health providers that interfere with the contraceptive chosen by the client.

Health providers are giving implants out of the interest of the client that is even if the client preferred injectable, the health provider enforces her to take long acting mainly the implants. FGD participants again added that if the client still refuses to use of implants, she must go back without any contraceptive.

Majority of health professionals prefer us to use the three or fiveyear contraceptive; for example, the health provider was informed for my friend to take the contraceptive inserted into the arm, but she refuses them and turns back without taking any contraceptive."Female, 30 years, implanon user.

Information obtained from health professionals indicates that the overall direction of the family planning program is to shift all short-acting users into a long acting users.

Our objective is to shift from short term to long term contraceptive, but this is not by force; starting from myself, we are requesting mothers to shift because this is a norm. In the previous time, health professionals decide the contraceptives that one mother should take, but now we are ruling by the principle "a mother should take the contraceptive she prefers. Male, 45 years, diploma. Another problem is resistance of health providers to remove the implants and IUCD at any time that the mother has been requested. This makes women to resist intake of long acting contraceptives that ultimately leave risks for future ignorance. Similarly, resistance of health provider led mothers for an unnecessary financial expenses because, they are enforced to remove it in private clinics, which is potentially expensive compare to government facility service. Mothers also expose to psychological distress, as well as a social and economic problem when a health provider not accepted their request to remove it on their demand.

There was one female whom I got her in holy water. Her clothe was sunk of blood. When I ask what her problem is, she told me "I took the five-year contraceptive then after my menses could not stop" then I said her to remove it at facility. However, she said me that the health providers told her "we already insert it for five years; the government brings this contraceptive to you to use it properly. It is not workable once to insert and to remove again. 'She was crying and feeling shame for other persons. Then I advise her to request them again by showing the blood. Then she 
told me "I already left with 8 months."I $t$ would be a crisis if this mother dies leaving five families behind" Female, 30 years.

The use of contraceptive by mother is also influenced by individual context of a woman. In this study three main factors namely lack of women self-empower, fear of complication and social issues have been identified as barrier for contraceptive preference.(see table one).

According to the data obtained from service providers, a majority of women have no power to choose the long-acting contraceptive independently. In other words, they need the permission from their husband. Some service providers assured that some contraceptive users came into the health facility after they had made a decision with their husband about what contraceptive they would like to use. When the health provider counsels her to use long acting contraceptives, the woman responded to him/her "let I first discuss with my husband, or let I think of it first."

FGD discussants also confirm that majority of women went to the health facility with pre informed choice made to the community in collaboration with their colleague and other member of the community. Hence become resistant for the counseling provided by the health care provider.

In my opinion, about $30 \%$ of mothers decide autonomously; even so, about $70 \%$ of mothers need permission from their husband. Even some mothers told us that their husband angry over them if they change contraceptive type; the husband said them 'I send you for needle (to mean injectable) so why did you change it?' so female alone cannot decide on the long acting."Female, 42 years, diploma nurse.

FGD Participants also say the first criteria that most mothers consider preferring contraceptive is the effect of the medicine on their health. If the contraceptive has minor or no complications following use, they demand it more, and before they took the contraceptive, first they collect information from their friends and reach a decision. Contraceptive users also prefer the contraceptive based on their plan, that for how long they would like to prevent their pregnancy, economic status and effect upon their health. Social issues like possessing of children, age of the mother, and fear of husband were also contributing to limit preference on some contraceptive.

Socio-cultural factors such as community information dynamics, women's dependency, social pressure (family \& peer pressure) and religion influence were identified as determinants of contraceptive preference. (See table one)

As well mentioned by participants, majority of the long-acting contraceptives, specifically IUCD has no-good acceptance by community, especially by female. Meanwhile, bad rumors on long acting contraceptives are highly inflated and disseminate vastly inside the community, and this led women to hate for most long acting contraceptives.

Socially, husband is expected to lead the house hold and any activity made by the member of the house hold is under the control over the husband. In other words, a woman cannot decide alone in case she needs contraceptive, unless she has got an approval from her husband. This was also similar in long acting contraceptive intake, i.e. unless she has got permission, she could not use long acting contraceptives.

Mothers in law and other relatives of the husband are another factor for not using long acting contraceptive because if the woman uses long acting and stay without pregnancy for longer time, they give her a nick name, in that they called her "bazra or mehan lam" to mean that the infertile Mule or infertile cow respectively; and even they triggered for her husband to divorce her if she waits long time without pregnancy.

Since the majority of the women are dependent on their husband, they did not prefer the long-acting contraceptive for the fear of its consequence like divorce, and physical violence. So the only alternative is taking the short-acting contraceptive and listening to the response from the husband and his relatives. If they remain silent, the mother can continue the short acting otherwise, she stops it and gives birth if any claim raised by her husband or his relatives.
Most mothers in-laws do not allow contraceptive use for her son's wife. They said 'why she only eat?', 'he is the only my son'" she must give birth' if she uses contraceptive and stays un pregnant, the mother an in-law calls her'she is like a horse, sleeping and eating only' Female, 42 years,

Religion is another problem for contraceptive preference because, according to participants, the religious leaders are not allowed to use any modern contraceptive in general and the condom in particular. The discussant also confirms that all religions (Muslim and Christian) are against any contraceptive use but what they advise is to remain faithfully and according to the Christian leaders opinion, using any contraceptive can prohibit from entrance to heaven that's why they advise their followers to be not use any contraceptive.

Muslim discussants describe that according to their religious advisor, let alone to use the condom it is strongly forbidden even to call its name. Besides this, most women, especially wives of the religious leader have not only a problem of contraceptive preference but also have problem of contraceptive use and with all this challenges they use it secretly when they need contraceptive. According to their view, short-acting contraceptives, particularly the injectable form is highly preferable to overcome the challenges.

\section{Discussion}

Four main factors determine contraceptive preference. These are community attitudes towards specific contraceptive, health care system problems, Individual context and Socio cultural problem. (See table one).

For analysis and clarity purpose, determinants are classified into four categories but these determinants are highly interrelated to each other. In overall, the contribution of community attitude takes the biggest role in determining contraceptive preference. Because, community attitude can influence by the practices of health care, cultural norms and religious education. For instance, if health providers are not skillful in insertion and removal, the community develops common attitude not to accept long acting contraceptives. Similarly, husband dominance is considered as socially and culturally acceptable behavior as a result taking contraceptives without his permission considered as bad attitude of the woman. Individual context to prefer contraceptive is highly linked with the other determinants.

Determinants of contraceptive preference are broad and interrelate to each other. Community attitude is one of the influential factors in determining contraceptive preference. Community attitude is an outcome of different interactions. The circulating information makes the community to have been common to withstand, and most mothers prefer the contraceptive based on pre-informed information. Though, each contraceptive has merits and demerits the contraceptive with high community acceptance has chosen better than its counterpart. This is due to the community strong social relation that is the community has a trend to share what someone feels, experienced, and suggested hence develop common view on each contraceptive.

Contraceptive users came to facility with pre informed decision from their colleague or families on what contraceptive they should use. Majority of contraceptive users ideally prefer injectable as this helps them to take hidden. SAC, particularly injectable has good community acceptance than LAPM for a reasons that SAC goes with flexible plan of the mother, and it is easy to control by the mother in case any conflict secondary to her contraceptive intake happened. For example, if her husband needs to get baby, she can stop it and get pregnant without any help from third person.

The other reason is that SAC were introduced into the community earlier than LAPM as a result contraceptive users may have more information and experience on SAC. Similarly, as confirmed by key informants, at this time the government interest is to shift from SAC to LAPM users but the community sees this approach in doubtful manner. Even some raise a question why special atten- 
tion has given to LAPM while all contraceptives are important to prevent pregnancy.

Health care system problems are another determinant factor for contraceptive preference, and this relates to refusal of providers to remove implants or IUCD, focusing only on women came to facility, lack of understanding what the community says about specific contraceptives, enforcing clients to accept long acting contraceptives, especially Implants and/or IUCD, and lack of skilled person are some among others. This finding is consistent with study done at different nations (UNFPA, 1994). When women enforced to take a contraceptive chosen by provider, this may return in a negative attitude in her life and she may not trust providers another time (Christine et al. 2012).

Individual context is the third determinant factor for contraceptive preference. When a mother chose a contraceptive, she considers different points before she prefers the contraceptive important for her. Some of the points that most women take into accountor has a role in contraceptive preference are numbered of children ever have, effect of the contraceptive on their health, husband's reaction, age, education and advise from colleagues. In this case, most women tend to prefer SAC because they do have long time existing experience.

Those mothers having more than three children, age above 35 years, and educated one are more confident to accept LAPM than their counterpart and this is could be due to feeling that such mother can assume they are secure in their marriage because her husband cannot divorce her as she has more children. They are also secure economically so that they cannot fear any consequence coming next to their decision. Similar to this study, research done in Bangladesh (M. Mahrab et al., 1996) also showed that long acting contraceptives use associates with husband approval, and educational attainment of the mother. Meanwhile, a research conducted in china (Lu Weiqun, 2008) indicates that a mother having more children tend to use long acting contraceptives than those with few children, and this has a similarity with this study.

Socio cultural problem such as husband, relatives or families role, religion and economic status have great role in contraceptive preference. Most contraceptives, particularly condoms are not acceptable by religious leaders in general and in the Muslim religion, in particular, which is similar with study conducted in Delhi (Neeti et al., 2010).

Most women need to take contraceptive hidden. Without husband's approval, it is impossible to takelong acting contraceptives and this could be associated with high desire of children by men, low education in the community and being considered the husband as a decision maker culturally. In the Ethiopian culture, women are expected to live in her husband's residence after marriage, and she is expected to obey all orders came from her husband, and this makes women to feel less empowered, dependent on their husband and being not the decision maker in their lives. Study done in rural Pakistan (Syed et al., 2012) indicates that men perceive the contraceptive use negatively and need more children than women and this is very similar with this finding.

\section{Conclusion}

The contraceptive method mix found to be highly skewed to single contraceptive indicating a need for further investigation on quality of the family planning program. Contraceptive preference is influenced by four main categories; namely community attitude towards the specific contraceptive, health care system Problem (focusing on long acting only, give more attention for coverage, poor counseling system, resistance to remove implants and influencing clients choice), Individual context, and socio cultural problem (husband pressure, mother in law and relatives influence, religion, and financial problem). (See table one)

Fear of infertility secondary to long acting contraceptive use, resistance of health providers for removal on time or as requested, being not familiar with long acting, hearing of bad rumor about long acting, and adaptation to short-acting contraceptives were the main reason among others to prefer short acting over long acting contraceptives. Some women have no a power to decide alone on long acting contraceptives; they always demand the approval of their husband to prefer long acting contraceptives. Though, condom has a dual purpose but participants say that it neither provided as contraceptive choice by the health provider nor demanded and used by the client. Most decisions for contraceptive preference are made at the community and highly influenced by husband.

\section{Competing with interests}

We all authors would like to declare that we have no competing interest in this manuscript.

\section{Authors' contributions}

MG has brought the concept into the study, carried out the overall design and execution of the study, performed data collection and statistical analysis. $\mathrm{AB}$ and DD have critically revised the design of the study, data collection techniques and helped the statistical analysis. All authors read and finally approved this manuscript for submission.

\section{Acknowledgement}

First, we would like to thank Addis Ababa University for financial and administrative support. We would like also to thank study participants for giving us their idea without reservation. Our gratitude extend to Dr. Mitke Molla from Addis Ababa University for her unlimited help during analysis. We would like also to forward our gratitude to Central Zonal office for cooperation and support.

\section{References}

[1] United States Agency for International Development. (USAID, 2009). Contraceptive projections and the donor gap; meeting the challenge.

[2] Andrew L., Jennifer A., Ntsiki M., and Mags B. (2006) Systematic review of contraceptive medicines "Does choice make a difference?" RHRU final report..

[3] United Nations Population Fund. (UNFPA, 2011). The Global Program to Enhance Reproductive Health Commodity Security.

[4] Mesganaw F. (2005). Quality of family planning in North West Ethiopia.Ethiop.J.Health Dev.; 19(5): 195-202.

[5] Eric E. Seibe, Jane T. Bertran, Tara M. Sullivan. (2007). Changes in Contraceptive Method Mix In Developing Countries. International family planning perspective; 33(3): 117-23.

[6] World Health Organization. (1993). Providing an appropriate contraceptive choices, what health worker need to know, $\mathrm{MCH} / \mathrm{FPP} / 93.3$

[7] John Ross, Karen Hardee, Elizabeth Mumford and Sherrine Eid. (2001). Contraceptive Method Choice in Developing Countries, International Family Planning Perspectives, 28(1):32-40. https://doi.org/10.2307/3088273.

[8] Charles picavet, Linda van, derleest enciel wijsen.(2011). Contraceptive decision -making background and outcome of contraceptive method, Rutgers WPF, 2-41.

[9] Jane T. Bertrand, Janet R., Tara M. Sullivan \& James Shelton. (2000). Skewed Method Mix: a measure of Quality in Family Planning Programs,.

[10] Federal Democratic Republic of Ethiopia Ministry of Health. (FDRE, 2011). National guideline for family planning services in Ethiopia.

[11] Mengistu A. Lakachew W. Yilma M. (2000). Improving the range of contraceptive choices in Tehuledere woreda, South Wollo zone, Amhara Regional State, rural Ethiopia.

[12] Ethiopian Demographic and Health Survey. (EDHS,2011).federal democratic republic of Ethiopia, central statistics agency.

[13] Federal democratic republic of Ethiopia. Central statistics authority, (CSAE,2007).population census commission, summary and statistical report.

[14] United Nations Population Fund. (UNFPA,1994). Quality of family planning services; evaluation finding, (3), 1-8. 
[15] Christine D. Kira L.,Allison K., Kevin G., JodyS. (2012). Women's preferences for contraceptive counseling and decision making, , Contraception 88, 250-56.

[16] M. Mehrab Ali, KhanM. Rahman. (1996). Determinants of contraceptive method-choice in rural Bangladesh, Center for health and population research, , working paper 117.

[17] LU WEIQUN. (2008). Contraceptive choice among married women in Guizhou province: socio-cultural and relationship factors,

[18] Neeti Rustagi, D.K. Taneja, Ravneet Kaur and G.K. Ingle. (2010) Factors affecting contraception among women in aminority community in Delhi: a qualitative study, , Health and population,33 (1), $10-15$.

[19] Syed KhurramAzmat, Ghulam Mustafa, Waqas Hameed,Muhammad Ali, Aftab Ahmed, Mohsina Bilgrami. (2012). Barriers and perceptions regarding different contraceptives and family planning practices amongst men and women of reproductive age in rural Pakistan: a qualitative study; Pakistan Journal of Public health, (2), 1.

\section{Annex one}

List of common misperceptions about contraceptive, as reported by focus group and in-depth interview discussants, Central zone, Tigray, Ethiopia, 2013.

- $\quad$ Pill and injectable can causes cancer for the women

- Pill can accumulate in uterus and make the mother infertile unless curettage has made.

- $\quad$ Pill is not good for the poor one and farmer mothers who do not have balanced diet

- Injectable contraceptive causes loss of sexual libido.

- Injectable contraceptive cause pregnancy out of uterus

- Injectable causes infertility and body spasm

- Condom causes partner disagreement

- The Lubricant of condom causes or induces pregnancy

- $\quad$ Disappeared IUCD is removed by operating the back bone

- IUCD Causes uterine prolapse

- IUCD has Discomfort during sex (for the male)

- Implant causes Paralysis of hand in which it is inserted in

- Implants causes body soreness, hair loss, leanness and overweight

- Implants is not important for heavy workers

- Long acting contraceptives lead to infertility

- The government intentionally brought the long acting to make the population infertile

- Using a contraceptive for longer time causes fetal anomalv (mental nhvsical)

Annexes. 1: English Version Qualitative Questionnaire. 